\title{
DISTÂNCIA PERCORRIDA POR JOGADORAS DE FUTEBOL DE DIFERENTES POSIÇÕES DURANTE UMA PARTIDA
}

\author{
GRAD. WAGNER POTTES MACIEL \\ Bacharel em Educação Física - Universidade Federal de Pelotas (UFPel) \\ (Pelotas - Rio Grande do Sul - Brasil) \\ e-mail:wageumaciel@hotmail.com
}

\begin{abstract}
ESP. EDUARDO LUCIA CAPUTO
Especialista em Treinamento Desportivo - Universidade Gama Filho (UGF)

Professor de Educação Física do Colégio São José (Pelotas - Rio Grande do Sul - Brasil)

e-mail: duducaputo@hotmail.com
\end{abstract}

\section{DR. MARCELO COZZENSA DA SILVA}

Doutor em Epidemiologia pelo Centro de Pesquisas Epidemiológicas da Faculdade de

Medicina da Universidade Federal de Pelotas (UFPel)

Professor adjunto da Escola Superior de Educação Física (ESEF) UFPel

Grupo de Estudos em Epidemiologia da Atividade Física (GEEAF/ESEF/UFPel)

(Pelotas - Rio Grande do Sul - Brasil)

e-mail: cozzensa@terra.com.br

\begin{abstract}
RESUMO
O objetivo do presente estudo foi determinar a distância total percorrida por jogadoras de futebol de campo de diversas posições durante uma partida. A amostra foi composta por I I atletas de um time de futebol feminino da cidade de Pelotas/RS, sendo a distância total percorrida verificada através da utilização de pedômetros. Foi encontrada diferença significativa entre a distância percorrida de meias e atacantes. A distância média percorrida no $1^{\circ}$ tempo foi maior que a média percorrida no $2^{\circ}(5,9 \mathrm{Km}$ versus $5,2 \mathrm{Km}$; $p<0,05)$. A distância percorrida apresentou correlação negativa com o percentual de gordura $(r=-0,6$; $p<0,05)$. A utilização de pedômetros mostrou ser eficiente para o objetivo proposto, dando a preparadores físicos e pesquisadores uma alternativa prática e barata para medição da mesma em atletas de futebol feminino.
\end{abstract}

PALAVRAS-CHAVE: Futebol; avaliação de desempenho; mulheres; treinamento desportivo. 


\section{INTRODUÇÃO}

O futebol de campo é uma modalidade esportiva coletiva e complexa, sendo que as diversas posições ou funções táticas exercidas determinam grande variabilidade individual no que diz respeito à intensidade e volume dos deslocamentos em partida e, consequentemente, às respostas fisiológicas frente ao jogo (BALIKIAN et al. , 2002). Para que o atleta possa atingir o melhor de sua forma desportiva ao longo da competição principal, Bompa (2002) ressalta que é importante a elaboração de um programa de treinamento que atenda às características do desporto.

Nos últimos anos tem-se dado muita importância ao componente físico do treinamento em futebolistas. Segundo Reilly (1996a), isso se deve em função desse fator de treino ser considerado alicerce para o desenvolvimento dos aspectos técnico e tático.

Dentre as capacidades mais requeridas pelo desporto encontram-se as capacidades aeróbia e anaeróbia, a força e a velocidade. Gorostiaga et al. (2004) afirmam que o futebol caracteriza-se por ser uma atividade intermitente, na qual há cerca de 12\% do envolvimento do metabolismo anaeróbio de alta intensidade e os outros $88 \%$ do metabolismo aeróbio. Segundo Weineck, (2000) o desenvolvimento do sistema aeróbio pode melhorar o desempenho físico, devido ao aumento da capacidade de recuperação e favorecer a manutenção de um ritmo ótimo de deslocamento durante o jogo.

Em um jogo de futebol, atletas masculinos percorrem em média I I Km, sendo que a distância percorrida ao longo do primeiro tempo é superior em 5\% com relação ao segundo tempo (EKBLOM, 1986; RIENZI et al., 2000). Em seu estudo, Krustrup et al. (2005) relataram uma média de 10,3 Km na distância percorrida para jogadoras de futebol.

De maneira geral, a distância percorrida por um jogador depende da qualidade do oponente, de considerações táticas e do grau de importância do jogo (BANGSBO et al. 199I; REILLY, 1996b). Adicionalmente, podemos considerar outros fatores como condições climáticas e níveis de treinamento.

Os métodos de treinamento aplicados durante o passar dos anos sempre vislumbraram a melhoria do rendimento de atletas masculinos de futebol, visto que a prática do mesmo foi proibida para mulheres por mais de uma década ( 1965 a 1978) (MOREL; SALLES, 2006; GOELLNER, 2005). A partir daí, o futebol feminino começou a ganhar força e se difundir em nosso país. Em 1996, na Olimpíada de Atlanta, o futebol feminino brasileiro conseguiu a quarta colocação abrindo espaço para que a mulher futebolista crescesse e as seleções nacionais passassem a evoluir a cada ano (MONTINGELLI, 2007). 
Nas últimas décadas muito se tem pesquisado sobre variáveis do desporto que influenciam diretamente, ou são influenciadas, pelo treinamento físico dos atletas de futebol masculino. Entretanto, muitas dessas variáveis apresentam-se de forma diferenciada para jogadores do naipe feminino, o que pode, se não avaliadas corretamente, levar a aplicação de treinamento fora dos padrões específicos para esse gênero. Além disso, a literatura científica sobre o futebol feminino carece de novas pesquisas sobre o tema.

Com isso, o presente estudo visa determinar a distância percorrida por jogadoras de futebol de diferentes posições durante uma partida.

\section{MATERIAL E MÉTODOS}

Este estudo caracteriza-se por ser do tipo observacional de corte transversal. A amostra foi composta por onze jogadoras de futebol feminino (três zagueiras; duas laterais; três meias; três atacantes) filiadas ao Esporte Clube Pelotas, selecionadas intencionalmente para participar da pesquisa. As jogadoras estavam disputando, no ano de 2009, duas competições oficiais de futebol: Copa do Brasil (CBF) e Campeonato Gaúcho (Liga de Futebol Feminino do Rio Grande do Sul).

Os sujeitos foram submetidos a testes antropométricos e de capacidade aeróbia máxima $\left(\mathrm{VO}_{2}\right.$ max), além de um questionário contendo informações referentes a características demográficas e posições de jogo. Para determinação da distância percorrida (desfecho) foram utilizados pedômetros da marca Yamax modelo sw700/701. O VO 2 max foi aferido através do teste de Léger \& Lambert (1982). O percentual de gordura (\% G) foi calculado pela fórmula proposta por Pollock et al. ( 1980 ) utilizando três dobras (triciptal, suprailiaca e coxa) e sua coleta foi realizada por meio de plicômetro científico da marca CESCORF com precisão de 0, I mm. peso corporal foi aferido através de balança da marca Welmy com precisão de I 00 gramas e a estatura através do estadiômetro da marca Welmy com precisão de $0,1 \mathrm{~cm}$. O Índice de Massa Corporal (IMC) foi calculado através da fórmula Peso (massa corporal em Kg) /estatura (em metros)².

Em data estabelecida, com uma semana de antecedência ao jogo utilizado para tomada de dados, em um dia de treino, foram realizados as seguintes testagens: verificação do peso e estatura das atletas e medida das dobras cutâneas triciptal, suprailiaca e coxa. Todas as medidas foram realizadas dentro do vestiário do clube, com as atletas vestindo short e top. Em seguida foi aferido o consumo máximo de oxigênio das jogadoras através do teste de Léger e Lambert (1982). O teste foi aplicado no próprio campo de futebol com as atletas utilizando tênis, sendo realizado por cinco atletas simultaneamente. 
Para verificação da distância percorrida, as atletas receberam, no dia do jogo, ainda no vestiário, um pedômetro que foi fixado à bermuda térmica que todas as jogadoras utilizavam por baixo do calção. As atletas realizaram o aquecimento com o material, mas os mesmos foram zerados momentos antes do início da partida. $\bigcirc$ número de passos indicado por cada aparelho de cada uma das jogadoras foi registrado pelo pesquisador ao final do primeiro tempo, quando as atletas saíam de campo para o vestiário. Os pedômetros foram, então, zerados para o início do segundo tempo da partida, onde, ao final do mesmo, os dados foram novamente anotados.

Para o cálculo da determinação da distância percorrida, foi realizada a multiplicação do número de passos totais durante a partida pela média da distância das passadas caminhando e correndo. A determinação da passada média (0,90 metros; $\mathrm{DP}=0,07)$ foi estabelecida através de teste piloto com a realização de repetidas tomadas de passadas de diferentes jogadoras caminhando e correndo em piso de areia. A média da distância da passada de caminhada foi somada a média da distância da passada de corrida e, então, foi realizada a determinação da média entre as duas.

A análise estatística foi realizada por intermédio do software estatístico SPSS versão I I .0, utilizando estratégias descritivas para representar valores médios e seus respectivos desvios-padrão. Para comparação entre médias foi utilizado o teste-t de Student. Análise de variância de uma entrada foi utilizada para verificar a diferença entre a distância percorrida nas diferentes posições de jogo. Para analisar a relação entre distância percorrida e percentual de gordura e distância percorrida e consumo máximo de oxigênio foi realizada uma análise de correlação de Pearson.

Foi garantido o direito de recusa às jogadoras selecionadas para a participação na pesquisa. Além disso, as que consentiram participar do estudo assinaram um Termo de Consentimento Livre e Esclarecido. Foi garantido a cada uma das participantes o sigilo das informações coletadas. A pesquisa foi enviada à apreciação do Comitê de Ética em Pesquisa da Faculdade de Educação Física da UFPel sob número de protocolo 1 10/20 10.

\section{RESULTADOS}

As atletas participantes apresentaram idade entre dezoito e vinte anos (2 I,0 $\pm 2,1$ anos), altura média de $162,6 \pm 4,9 \mathrm{~cm}$ e peso corporal médio de 58,7 \pm 10, I Kg. Essas médias podem ser observadas na Tabela I, assim como as médias de IMC, \%G e VO2 max.

Na Figura I são mostradas e comparadas as médias de distância percorrida pelas atletas nas diferentes posições do jogo. A análise de variância mostrou diferença apenas entre meias e atacantes ( $12,05 \mathrm{Km}$ VS 6,73Km, $p<0,05)$. 
A distância média percorrida em cada tempo de jogo foi respectivamente de $5,9 \mathrm{Km}\left(1^{\circ}\right.$ tempo $)$ e $5,2 \mathrm{Km}\left(2^{\circ}\right.$ tempo $)(p<0,05)$. A Figura 2 mostra graficamente esses valores, bem como a distância total percorrida em todo jogo.

Tabela I. Dados descritivos da amostra, apresentados em média com respectivosdesvios padrão por posição de jogo.

\begin{tabular}{|c|c|c|c|c|c|c|c|}
\hline & $N$ & $\begin{array}{l}\text { Idade } \\
\text { (anos) }\end{array}$ & $\begin{array}{l}\text { Peso } \\
(\mathrm{Kg})\end{array}$ & $\begin{array}{l}\text { Altura } \\
(\mathrm{cm})\end{array}$ & $\begin{array}{l}\text { IMC } \\
\left(\mathrm{Kg} / \mathrm{m}^{2}\right)\end{array}$ & $\% G$ & $\begin{array}{l}\mathrm{VO}_{2 \max } \\
\left(\mathrm{ml} \cdot \mathrm{kg}^{-1} \cdot \mathrm{min}^{-1}\right)\end{array}$ \\
\hline Zagueiras & 3 & $21,0 \pm 1,0$ & $56,4 \pm 4,0$ & $|6|, 7 \pm 4,7$ & $21,6 \pm 2,2$ & $23,9 \pm 5,1$ & $42,9 \pm 5,3$ \\
\hline Laterais & 2 & $22,0 \pm 1,4$ & $65,6 \pm 18,2$ & $164,5 \pm 4,9$ & $24,1 \pm 5,3$ & $21,8 \pm 4,2$ & $47,6 \pm 4,2$ \\
\hline Meias & 3 & $20,3 \pm 2,3$ & $52,3 \pm 2,8$ & $159,3 \pm 1,5$ & $20,6 \pm 1,1$ & $21,0 \pm 2,3$ & $45,6 \pm 3,2$ \\
\hline Atacantes & 3 & $21,0 \pm 3,6$ & $62,7 \pm 13,3$ & $165,7 \pm 7,0$ & $22,7 \pm 3,7$ & $27,5 \pm 1,5$ & $38,5 \pm 5,6$ \\
\hline Total & & $21,0 \pm 2,1$ & $58,7 \pm 10,1$ & $162,6 \pm 4,9$ & $22,1 \pm 2,9$ & $23,3 \pm 3,9$ & $43,3 \pm 5,3$ \\
\hline
\end{tabular}

Figura I. Distância média percorrida nas diferentes posições de jogo.



*Indica diferença estatística na comparação entre meia e atacante $(p<0,05)$.

Figura 2. Distância média percorrida no total, no primeiro tempo e no segundo tempo de jogo.

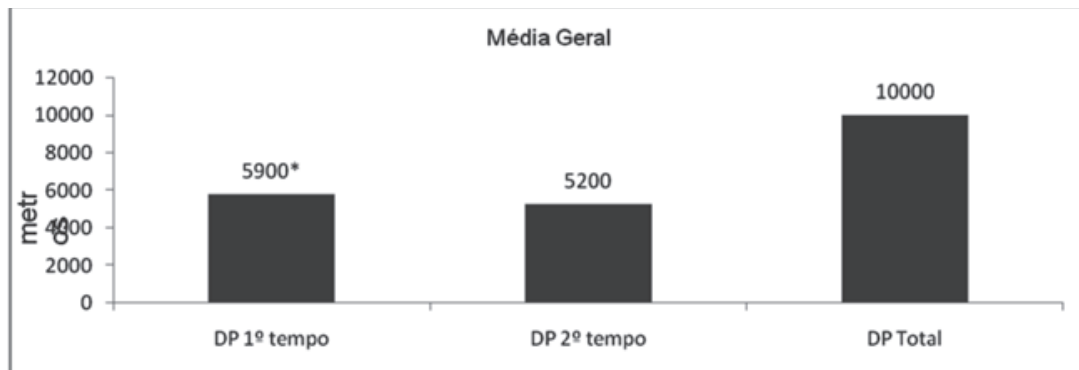

*Indica diferença estatística entre a distância percorrida no $1^{\circ}$ tempo e a distância percorrida no $2^{\circ}$ tempo $(p<0,05)$. 
Na análise de correlação entre a distância total percorrida e \%G e distância total percorrida e VO2max foram encontrados valores de, respectivamente, $r=-0,6$ $(p<0,05)$ e $r=0,4(p>0,05)$.

\section{DISCUSSÃO}

As atletas avaliadas em nosso estudo apresentaram valores médios de percentual de gordura e IMC de 23,3 $\pm 3,9 \%$ e $22,1 \pm 2,9 \mathrm{Kg} / \mathrm{m}^{2}$. Com relação a essas variáveis nossos achados vão de encontro ao estudo de Fornetti et al. (1999) que encontraram valores de $21,8 \%$ e 23, I Kg/m² para jogadoras de futebol universitárias. Ainda com relação ao percentual de gordura, nossos dados corroboram estudos realizados com atletas de futsal do sexo feminino e jogadoras de futebol de campo da seleção inglesa, que apresentaram respectivamente 23,2\% e 21 , I \% (QUEIROGA et al., 2005; DAVIS; BREWER, 1993). Entretanto, Buscariolo et al. (2008) relatam valores de 19,03\%. Esse mesmo autor coloca que as diferenças encontradas entre os valores na literatura podem se dar em função das técnicas utilizadas para avaliação das atletas.

A média de $\mathrm{VO}_{2}$ max das jogadoras testadas encontra-se condizente com os valores médios dessa capacidade descritos por outros estudos. Em estudo de revisão a respeito de futebol feminino, Stolen et al. (2005) encontraram valores de $\mathrm{VO}_{2}$ max que variaram de $38,6 \mathrm{ml} \cdot \mathrm{kg}^{-1} \cdot \mathrm{min}^{-1}$ à $57,6 \mathrm{ml} \cdot \mathrm{kg}^{-1} \cdot \mathrm{min}^{-1} \mathrm{em}$ atletas de elite de países como Dinamarca, Noruega, Austrália e Inglaterra. A variabilidade existente entre os dados pode ser resultado da diferença entre o nível de condicionamento físico das atletas tendo em vista que o futebol feminino é um esporte ainda em desenvolvimento, não sendo profissional em todos os locais de prática.

No que se refere à distância percorrida, Krustrup et al. (2005) relataram em seu estudo, com jogadoras profissionais de futebol dinamarquesas, uma média percorrida de 10,3 Km em uma partida. Esse resultado corroborou com o nosso achado, onde obtivemos média de 10,0 $\pm 2,7 \mathrm{~km}$ por partida.

Em nosso estudo encontramos diferença entre a distância média percorrida em cada um os dois tempos do jogo, sendo a distância média percorrida no primeiro tempo maior do que a distância média percorrida no segundo tempo. Rienzi et al. (2000) encontraram distâncias maiores percorridas na primeira metade do jogo. Possivelmente, este comportamento se deve à degradação progressiva do glicogênio muscular ao longo da partida, o que poderia implicar em uma queda do rendimento físico das atletas na segunda parte da partida (BANGSBO, 1994).

Como no presente estudo, Krustup et al. (2005) não encontraram correlação significativa de $\mathrm{VO}_{2}$ max e distância total percorrida em atletas de elite da Dinamarca 
$(r=0,20 ; p>0,05)$. Em nosso estudo o percentual de gordura apresentou correlação negativa com a distância total percorrida. Poucos estudos analisaram a relação entre parâmetros antropométricos e indicadores de desempenho. Osiecki et al. (2007) ao estudarem essa relação em atletas masculinos de futebol de campo não encontraram relação entre o percentual de gordura, indicadores como $\mathrm{VO}_{2}$ max e velocidade de limiar com distância no Yo-Yo teste. Tais fatos indicam a necessidade de maiores estudos investigativos com relação a esse tema.

A metodologia adotada nesse estudo apresenta algumas limitações tais como o não acompanhamento da frequência cardíaca e níveis de lactato, o que subsidiaria o entendimento do grau de exigência as quais as atletas foram submetidas durante a partida. Aliado a isso, foi utilizada apenas uma única partida para a coleta de dados, o que poderia super ou subestimar a real distância percorrida em jogo, visto que essa distância pode variar de acordo com o adversário, competição, clima, entre outros. $\bigcirc$ valor médio da passada multiplicado pelo número de passos, na determinação da distancia percorrida não é tão preciso quanto uma medida realizada por meio de GPS.

Apesar disso os valores encontrados são condizentes com os achados de outros estudos de diferentes países.

\section{CONCLUSÃO}

O presente estudo demonstrou que a distância total média percorrida por jogadoras de uma equipe não profissional da cidade de Pelotas foi de 10,0 Km, sendo superior no primeiro tempo de jogo. Além disso, à medida que diminuiu o \%G das atletas aumentou a distância percorrida pelas mesmas. Apesar de ter sido coletado durante uma única partida e em uma única equipe, os resultados podem servir de subsídio para a realização de novas pesquisas, utilizando instrumentos mais precisos, dando suporte para a prescrição de treinamentos que possibilitem as atletas percorrerem essa distância com menor desgaste físico ou, até mesmo, aumentar os limites percorridos.

Distance covered by female soccer players of different positions during a match

ABSTRACT: The aim of this study was to verify the total distance covered by soccer players of different positions during a match. The sample consisted of I I athletes from a soccer team of Pelotas city / RS and the total distance was measured by pedometers. Significant difference distance was verified between midfielders and strikers. The average distance in the Ist time was greater than the mean distance in $2 \mathrm{nd}(5.9 \mathrm{~km} v \mathrm{v} .5 .2 \mathrm{~km}, p<0.05)$. The distance was negatively correlated with fat percentage $(r=-0.6, p<0.05)$. The use of pedometers was 
effective for the proposed goal, giving the trainers and researchers a practical and affordable alternative to the measurement in female soccer players.

KEY WORDS: soccer; employee performance appraisal; women; sports training.

\section{Distancia recorrida por los jugadores de fútbol femenino de diferentes durante um partido}

RESUMEN: El objetivo de este estudio fue determinar la distancia total recorrida por el campo los jugadores de fútbol de diferentes posiciones durante un partido. La muestra consistió de I I atletas en un equipo de fútbol, la ciudad de Pelotas / RS, y la distancia total recorrida verificado mediante el uso de podómetros. Diferencia significativa entre la distancia de media y los atacantes. La distancia media en la l a vez fue mayor que la distancia media en $2(5.9 \mathrm{~km}$ frente a 5,2 km, p <0,05). La distancia recorrida se correlacionó negativamente con el porcentaje de grasa $(r=-0,6, p<0,05)$. El uso de podómetros fue efectiva para el objetivo propuesto, dando a los formadores y los investigadores una alternativa práctica y económica a la misma medición en jugadores de fútbol femenino.

PALAVRAS CLAVE: fútbol; evaluación del rendimiento de empleados; mujeres; entrenamiento deportivo.

\section{REFERÊNCIAS}

BALIKIAN, P. et al. Consumo máximo de oxigênio e limiar anaeróbio de jogadores de futebol: comparação entre as diferentes posições. Revista Brasileira de Medicina do Esporte, São Paulo, v. 8, n. 2, p.32-36, 2002.

BANGSBO J. et al. Active profile of competition soccer. Canadian Journal Sports Sciences, Cidade, v.16, p. I10-116, 1991.

BANGSBO, J. The physiology of soccer, with special reference to intense intermittent exercise. Acta Physiologica Scandinavica: an international journal of physiological sciences, v. I 5 I, suplementum 619, 1994.

BOMPA, T. O. Periodização: teoria e metodologia do treinamento. São Paulo: Phorte Editora, 2002.

BUSCARIOLO, F. F. et al. comparação entre os métodos de bioimpedancia e antropometria para avaliação da gordura corporal em atletas do time de futebol feminino de Botucatu/SP. Revista Simbio-Logias, v. I, n. I, p. I22- 129, 2008.

DAVIS, J. A.; BREWER, J. Applied physiology of female soccer players. Sports Medicine, v. 16, n. 3, p. 180-189, 1993. 
EKBLOM B. Applied physiology of soccer. Sports Medicine, v. 3, p.50-60, 1986.

FORNETTI, W. C. et al. Reliability and validity of body composition measures in female athletes. Journal of Applied Physiology, v.87, p. | | |4- | |22, 1999.

GOELLNER, S. V. Mulheres e futebol no Brasil: entre sombras e visibilidades. Revista Brasileira de Educação Física e Esporte, São Paulo, v. 19, n. 2, p.|43- I 5 |, abr./jun. 2005.

GOROSTIAGA, E. et al. Strength training effects on physical performance and serum hormones in young soccer players. European Journal Applied Physiology, v. 9I, n. 5-6, p. 698-707, 2004.

KRUSTRUP, P. et al. Physical Demands during an Elite Female Soccer Game: Importance of Training Status. Medicine and Science in Sports and Exercise, v. 37, n. 7, p. 1242- 1248 , 2005.

LÉGER, L. A; LAMBERT, J. A maximal multistage 20-m shuttle run test to predict VO2 max. European Journal of Applied Physiology and Occupational Physiology, v. 49, p. $1-12,1982$.

MOREL, M; SALLES, J. G. C. Futebol feminino. Atlas do esporte no Brasil. In: CONFEF: Atltas do esporte no Brasil. Rio de Janeiro: CONFEF, p. 8264-8265. 2006.

NUNES, M. M.; PEREIRA, J. G. A evolução da força reativa em futebolistas de 16- 8 anos. Horizonte XIV, n. 83, p. 24-8.

OSIECKI, R. et al. Parâmetros antropométricos e fisiológicos de atletas profissionais de futebol. Revista da Educação Física da Universidade Estadual de Maringá, Maringá, v. I8, n. 2, p. 177-182, 2007.

POLLOCK, M. L. et al. Generalized equations for predicting body density of women. Medicine and Science in Sports and Exercise, v. 12, n. 3, p. 175-81, 1980.

QUEIROGA, M. R.; ROMANZINI, S. Perfil antropométrico de atletas de futsal feminino de alto nível competitivo conforme a função tática desempenhada no jogo. Revista Brasileira de Cineantropometria e Desempenho Humano, Florianópolis, v.7, n. I, p30-34, 2005.

REILLY, T. Ed. Science and soccer. London: E\&FN Spon, $1996 \mathrm{a}$.

REILLY, T. Motion characteristics. In: EKBLOM, B. Football (soccer). Oxford: Blackwell Scientific, p. 31-42, 1996 b.

WEINECK, J. Futebol total: o treinamento físico no futebol. Guarulhos: Phorte Editora, 2000 . 
Recebido: 26 mar. 2010

Aprovado: 07 dez. 2010

Endereço para correspondência:

Marcelo Cozzensa da Silva

Rua Luiz de Camões, 625

Bairro Três Vendas

Pelotas RS.

CEP: 96055-630. 